Tropical Journal of Pharmaceutical Research February 2021; 20 (2): 433-439

ISSN: $1596-5996$ (print); 1596-9827 (electronic)

(C) Pharmacotherapy Group, Faculty of Pharmacy, University of Benin, Benin City, 300001 Nigeria.

\title{
Effect of general and sub-arachnoid anesthesia on the incidence of postoperative delirium and cognitive impairments in elderly Chinese patients
}

\author{
Wei-Xia Ren, Ran-Ran Wu* \\ Department of Anesthesiology, Suzhou Ninth People's Hospital, Soochow University, Suzhou 215200, Jiangsu, China \\ *For correspondence: Email: ran.wu1983@yahoo.com; Tel/Fax: 0086-13270258730 \\ Sent for review: 28 September 2020 \\ Revised accepted: 22 January 2021
}

\begin{abstract}
Purpose: To investigate the effect of general and subarachnoid (spinal) anesthesia on the incidence of postoperative delirium and cognitive impairments in elderly Chinese patients.

Methods: Elderly Chinese patients $(n=281)$ aged $65-79$ years (mean age $=74.12 \pm 4.15$ years) who underwent proximal femoral fracture surgery were recruited over a 1-year period for this study. The patients were evaluated using neuropsychological assessment battery (NAB) $24 h$ before surgery, and on the first day 1 month after surgery. Data on activity of daily living (ADL) (in this case toileting at the time of discharge) were recorded and analyzed.

Results: There was no significant difference in the number of patients that developed postoperative delirium between the two anesthesia groups $(p>0.05)$. Although the trail making test (TMT) scores (parts $A$ and $B$ ) were increased on the first day 1 month after surgery, there were no significant differences in NAB results between the two groups $(p>0.05)$. Patients who received subarachnoid (spinal) anesthesia had significantly higher dependency for toileting at the time of discharge than those who received general anesthesia $(p<0.05)$.

Conclusion: These results show that general and subarachnoid (spinal) anesthesia do not cause postoperative delirium and cognitive dysfunction in elderly Chinese patients who underwent proximal femoral fracture surgery.
\end{abstract}

Keywords: Anesthesia, Cognitive function, Delirium, Elderly patients, Surgery

\begin{abstract}
This is an Open Access article that uses a fund-ing model which does not charge readers or their institutions for access and distributed under the terms of the Creative Commons Attribution License (http://creativecommons.org/licenses/by/4.0) and the Budapest Open Access Initiative (http://www.budapestopenaccessinitiative.org/read), which permit unrestricted use, distribution, and reproduction in any medium, provided the original work is properly credited.

Tropical Journal of Pharmaceutical Research is indexed by Science Citation Index (SciSearch), Scopus, International Pharmaceutical Abstract, Chemical Abstracts, Embase, Index Copernicus, EBSCO, African Index Medicus, JournalSeek, Journal Citation Reports/Science Edition, Directory of Open Access Journals (DOAJ), African Journal Online, Bioline International, Open-J-Gate and Pharmacy Abstracts
\end{abstract}

\section{INTRODUCTION}

Postoperative cognitive impairment $(\mathrm{POCl})$ is a functional mental disorder that arises after a surgical procedure [1]. It affects verbal and visual memories and leads to lack of concentration and attention deficit [2]. Postoperative cognitive impairment is characterized by high morbidity and mortality among elderly patients [3]. Results of studies on $\mathrm{POCl}$ are divergent in their conclusions $[3,4]$. It has been speculated that the incidence of $\mathrm{POCl}$ after hip fracture surgery will continue to increase in China up to 2050 . Temporal fluctuations peak during the initial postoperative period and return to the initial state within a week after surgery [1]. The severity of $\mathrm{POCl}$ is determined by co-morbidities in patients and type of surgery $[2,5]$. The type of anesthesia 
used during surgery is thought to contribute to $\mathrm{POCl}$. Regional anesthesia is generally preferred for elderly patients by most anesthesiologists [6]. However, studies have shown that there is no marked difference in incidence of $\mathrm{POCl}$ several weeks after surgery between patients on general and regional anesthesia [4,7]. Although anesthetics used in surgeries have profound effect on the central nervous system (CNS), it is difficult to describe the individual effect [3]. The actual contribution of anesthesia to $\mathrm{POCl}$ is largely unknown [8].

Hip or proximal femoral fracture refers to fracture of the femur in bone areas distal to the articular cartilage of the hip, to a level approximately $5 \mathrm{~cm}$ below the lower border of the lesser trochanter [9]. Proximal femoral fracture impacts on the quality of life of patients [10].

The aim of this study was to investigate the effect of general and subarachnoid (spinal) anesthesia on the incidence of postoperative delirium and cognitive impairments in elderly Chinese patients.

\section{METHODS}

\section{Materials}

Fentanyl was obtained from Taylor Pharmaceuticals (USA). Propofol was product of Fresenius Kabi AG (Germany). Rocuronium was bought from Hospira (USA). Spinal cord needle (Quincke $25 \mathrm{G}$ ) was purchased from Becton, Dickinson, and Company Ltd. (USA). Ropivacaine was product of AstraZeneca (UK), while epinephrine was obtained from Mylan (USA).

\section{Patients and general information}

Elderly patients $(n=281)$ aged $65-79$ years (mean age $=74.12 \pm 4.15$ years) who underwent proximal femoral fracture surgery in Suzhou Ninth People's Hospital, Soochow University, Suzhou, Jiangsu, China, were recruited over a 1year period for this study.

Patients with disease(s) of the CNS (dementia and Parkinson's disease), as well as those on antidepressant therapy, were excluded from the study. There were 130 male patients and 151 female patients. The study protocol was approved by Institutional Ethical Committee of Suzhou Ninth People's Hospital, Soochow, China, and the study guidelines were in accordance with the laws of China and Declaration of Helsinki (2008). Written informed consents were signed by the patients and their family members.

\section{Experimental design}

The patients were randomly assigned to 2 groups: general anesthesia and subarachnoid anesthesia groups. Patients in general anesthesia group $(n=154$, mean age $=74.12 \pm$ 4.15 years) received fentanyl at a dose of 3.5 $\mu \mathrm{g} / \mathrm{kg}$ body weight (bwt) and $1.5 \mathrm{mg}$ propofol $/ \mathrm{kg}$ bwt. Intubation was facilitated with $0.6 \mathrm{mg}$ rocuronium $/ \mathrm{kg}$ bwt. Mechanical ventilation was carried out with a $50 \%$ oxygen-air mixture to achieve tidal volume of $6-8 \mathrm{~mL} / \mathrm{kg}$ bwt, respiratory rate of $10-12$ breaths/min, oxygen saturation $>97 \%$, and end-tidal carbon dioxide of $35 \mathrm{mmHg}$.

Subarachnoid anesthesia group patients ( $\mathrm{n}=$ 127 , mean age $=73.12 \pm 6.15$ years) with L3-L4 or L4-C5 intervertebral space were administered $20 \mu \mathrm{g}$ fentanyl $/ \mathrm{kg}$ bwt and $0.75 \%$ ropivacaine via spinal puncture. In the event that hypotension (reduction in systolic blood pressure $>30 \%$ from pre-procedural value) occurred, $1 \mathrm{mg}$ epinephrine/kg bwt was intravenously injected. The patients were evaluated using NAB $24 \mathrm{~h}$ before surgery, and on the first day after 1 month of surgery.

\section{Assessment of confusion}

Acute onset and fluctuating course, inattentiveness, disorganized thought, and altered level of consciousness were used for deciding the absence or presence of delirium. Confusion assessment was performed daily after surgery for 7 days [11].

\section{Mini-mental state examination (MMSE)}

A total of 11 questions covering five areas of cognitive function (temporal orientation, spatial orientation, attention, calculation, recall, and language) were used for MMSE. The maximum score was 30 and score < 24 was considered as cognitive impairment [12].

\section{Beck Depression Inventory-II}

A total of 21 items were rated on a 0 to 3 scale. The total score ranged from 0 to 63 . Scores $\geq 20$ were taken as indicative of depression [13].

\section{Trail making test (TMT)}

Part A: Patients were made to draw a line serially connecting Chinese numerals 1 to 25 . Ability to complete the task within $150 \mathrm{sec}$ was 
indicative of normal state or absence of cognitive impairment.

Part B: Patients were made to draw lines linking 12 Chinese zodiac animals and their pictures. Ability to complete the task within $150 \mathrm{sec}$ was indicative of normal state or absence of cognitive impairment [14].

\section{Auditory-verbal learning test (AVLT)}

The AVLT measures verbal learning in terms of immediate and delayed free recall, recognition, and retroactive and proactive interference [15]. The AVLT score was calculated and scores $\leq 23$ were considered normal [16].

\section{Digit symbol substitution test (DSST)}

The DSST requires response speed, sustained attention, visual spatial skills and set shifting. Patients were made to draw lines linking Chinese symbols and digits within 2 min. Scores $\geq 80$ were taken as normal [17]. The higher the score, the better the patient's performance.

\section{Verbal fluency test (VFT)}

Patients were asked to name animals within 1 min. Ability to name at least 15 animals within the stipulated time was indicative of normal state or absence of cognitive impairment [18].

\section{Measurement of ADL (toileting)}

Toileting as an index of ADL was used as a measure of patient's independence. It was classified into total dependence, partial dependence, and independence. Data on ADL at the time of discharge were recorded and analyzed.

\section{Statistical analysis}

The sample size was calculated based on the assumption that $7 \pm 1 \%$ patients would develop postoperative delirium. Power analysis was performed using an online calculator, assuming $\alpha$ $=0.05$ with a power $(\beta)$ of $80 \%$.

Qualitative data are expressed as relative frequency (percentage), while quantitative data are presented as mean \pm standard deviation (SD). Groups were compared using Student's $t$ test, Chi-squared test, Fisher exact test, and Mann-Whitney test as appropriate. All statistical analyses were performed using SPSS (25.0).
Values of $p<0.05$ were taken as indicative of statistically significant differences.

\section{RESULTS}

\section{Clinical and demographic characteristics of patients}

There were no significant differences in patients' preoperative demographic characteristics, clinical conditions, NAB outcome, and operative characteristics between the two anesthesia groups $(p>0.05$; Table 1$)$.

\section{Results of neuropsychological tests battery}

There was no significant difference in the number of patients who developed postoperative delirium between the two anesthesia groups $(p>0.05)$. Although the TMT scores (parts $A$ and $B$ ) were increased on the first day 1 month after surgery, there were no significant differences in NAB results between the two groups $(p>0.05)$. These results are shown in Table 2.

\section{ADL results}

Patients who received subarachnoid (spinal) anesthesia had significantly higher dependency for toileting at the time of discharge than those who received general anesthesia $(p<0.05$; Table 3).

\section{DISCUSSION}

Postoperative cognitive impairment $(\mathrm{POCl})$ is a common adverse event after surgery. Its manifestations are subtle and diverse, depending on the particular cognitive domains that are affected. The diagnosis of $\mathrm{POCl}$ requires both pre- and postoperative psychometric testing. Elderly patients in particular are vulnerable to memory disturbances and other types of cognitive impairment after surgical operation. Emergence from anesthesia is often accompanied by signs of delirium such as fluctuating mental status and inattentiveness. Several studies have evaluated the effects of general anesthesia and non-general anesthesia on POCl. However, the results reported in these studies are inconsistent. The cerebral cortex is the basis of cognition. Factors that cause functional abnormalities in the cerebral cortex result in cognitive impairment $[2,3]$. The clinical manifestations of $\mathrm{POCl}$ range from mild cognitive abnormalities to severe memory impairment such as loss of judgment and personality changes. 
Table 1: Preoperative demographic characteristics, clinical conditions, neuropsychological assessment battery and operative characteristics $(n, \%)$

\begin{tabular}{|c|c|c|c|c|}
\hline \multirow{3}{*}{ Parameter } & & \multicolumn{2}{|c|}{ Anesthesia group } & \multirow{3}{*}{$P$-value } \\
\hline & & \multirow{2}{*}{$\begin{array}{c}\text { General } \\
\mathrm{n}=154\end{array}$} & \multirow{2}{*}{$\begin{array}{c}\text { Subarachnoid (spinal) } \\
\mathrm{n}=127\end{array}$} & \\
\hline \multirow{2}{*}{\multicolumn{2}{|c|}{ Age (years) }} & & & \\
\hline & & $74.12 \pm 4.15$ & $73.12 \pm 6.15$ & \\
\hline \multirow{2}{*}{ Sex } & Male & $69(45)$ & $61(48)$ & \\
\hline & Female & $85(55)$ & $66(52)$ & 0.631 \\
\hline \multirow[t]{2}{*}{ Weight (kg) } & & $59.22 \pm 7.82$ & $60.23 \pm 6.45$ & 0.245 \\
\hline & Primitive & $65(42)$ & $49(38)$ & \\
\hline \multirow[t]{2}{*}{ Education } & $\begin{array}{l}\text { Below } \\
\text { graduation }\end{array}$ & $55(36)$ & $48(38)$ & 0.827 \\
\hline & $\begin{array}{l}\text { Graduate } \\
\text { and above }\end{array}$ & $34(22)$ & $30(24)$ & \\
\hline \multirow{3}{*}{ Ethnicity } & $\begin{array}{l}\text { Han } \\
\text { Chinese }\end{array}$ & $139(90)$ & $115(90)$ & \multirow{3}{*}{0.992} \\
\hline & $\begin{array}{l}\text { Mongolian } \\
\text { Tibetan }\end{array}$ & $\begin{array}{l}12(8) \\
2(1)\end{array}$ & $\begin{array}{l}9(7) \\
2(2)\end{array}$ & \\
\hline & $\begin{array}{l}\text { Uighur } \\
\text { Muslim }\end{array}$ & $1(1)$ & $1(1)$ & \\
\hline \multirow{3}{*}{$\begin{array}{l}\text { American Society of } \\
\text { Anesthesiologists status }\end{array}$} & 1 & $67(43)$ & $55(43)$ & \multirow{3}{*}{0.998} \\
\hline & II & $69(45)$ & $57(45)$ & \\
\hline & III & $18(12)$ & $15(12)$ & \\
\hline \multirow{3}{*}{$\begin{array}{l}\text { New York Heart Association } \\
\text { status }\end{array}$} & 1 & $62(40)$ & $51(40)$ & \multirow{3}{*}{0.947} \\
\hline & II & $71(46)$ & 57 (45) & \\
\hline & III & $21(14)$ & 19 (15) & \\
\hline \multicolumn{2}{|l|}{ Hypertension } & $55(36)$ & $42(33)$ & 0.706 \\
\hline \multicolumn{2}{|l|}{ Diabetes } & $25(16)$ & 23 (18) & 0.751 \\
\hline \multicolumn{2}{|l|}{ Asthma } & $7(5)^{\prime}$ & $6(5)$ & 0.998 \\
\hline \multicolumn{2}{|c|}{ Chronic obstructive pulmonary disease } & $5(3)$ & $2(2)$ & 0.463 \\
\hline \multicolumn{2}{|c|}{ Duration of Surgery (min) } & $65.00 \pm 11.00$ & $68.00 \pm 15.00$ & 0.055 \\
\hline \multicolumn{2}{|l|}{ RBC transfusion } & $18(12)$ & $17(13)$ & 0.719 \\
\hline \multicolumn{2}{|l|}{ Hospital stay (days) } & $9.15 \pm 2.14$ & $9.02 \pm 2.15$ & 0.613 \\
\hline \multicolumn{2}{|l|}{ Mini-mental state examination } & $25.62 \pm 1.45$ & $25.71 \pm 1.18$ & 0.574 \\
\hline \multicolumn{2}{|l|}{ Beck Depression Inventory-II } & $6.85 \pm 2.81$ & $6.89 \pm 2.85$ & 0.906 \\
\hline \multicolumn{2}{|l|}{ Trail-making test Part A (sec) } & $89.15 \pm 12.15$ & $88.47 \pm 13.45$ & 0.657 \\
\hline \multicolumn{2}{|l|}{ Trail-making test Part B (sec) } & $112.43 \pm 14.15$ & $114.52 \pm 15.43$ & 0.238 \\
\hline \multicolumn{2}{|l|}{ Auditory-verbal learning test } & $17.14 \pm 1.42$ & $17.47 \pm 1.52$ & 0.061 \\
\hline \multicolumn{2}{|l|}{ Digit symbol substitution test } & $95.43 \pm 7.11$ & $95.44 \pm 6.45$ & 0.991 \\
\hline \multicolumn{2}{|l|}{ Verbal fluency test } & $18.89 \pm 1.02$ & $18.93 \pm 1.15$ & 0.758 \\
\hline
\end{tabular}

Table 2: Results of NAB 1 month after proximal femoral fracture surgery

\begin{tabular}{|c|c|c|c|c|c|c|c|}
\hline \multirow{3}{*}{ Parameter } & \multicolumn{6}{|c|}{ Anesthesia group } & \multirow{3}{*}{$\begin{array}{c}\text { Comparisons } \\
\text { between groups at } \\
\text { EL } \\
P \text {-value }\end{array}$} \\
\hline & \multicolumn{3}{|c|}{$\begin{array}{c}\text { General } \\
\mathrm{n}=154\end{array}$} & \multicolumn{3}{|c|}{$\begin{array}{c}\text { Subarachnoid (spinal) } \\
\mathrm{n}=127\end{array}$} & \\
\hline & BL & EL & $P$-value & BL & EL & $P$-value & \\
\hline $\begin{array}{l}\text { Mini-mental state } \\
\text { examination }\end{array}$ & $\begin{array}{l}25.62 \pm \\
1.45\end{array}$ & $\begin{array}{c}25.12 \pm \\
1.52\end{array}$ & 0.300 & $\begin{array}{l}25.71 \pm \\
1.18\end{array}$ & $\begin{array}{c}25.45 \pm \\
1.25\end{array}$ & 0.089 & 0.051 \\
\hline $\begin{array}{l}\text { Beck Depression } \\
\text { Inventory II }\end{array}$ & $\begin{array}{c}6.85 \pm \\
2.81\end{array}$ & $\begin{array}{l}6.91 \pm \\
2.85\end{array}$ & 0.853 & $\begin{array}{l}6.89 \pm \\
2.85\end{array}$ & $\begin{array}{l}7.15 \pm \\
2.95\end{array}$ & 0.476 & 0.489 \\
\hline $\begin{array}{l}\text { Trail-making test } \\
\text { Part A (sec) }\end{array}$ & $\begin{array}{c}89.15 \pm \\
12.15\end{array}$ & $\begin{array}{c}94.22 \pm \\
15.47^{*}\end{array}$ & 0.002 & $\begin{array}{c}88.47 \pm \\
13.45\end{array}$ & $\begin{array}{c}97.42 \pm \\
16.48^{*}\end{array}$ & $<0.0001$ & 0.093 \\
\hline $\begin{array}{l}\text { Trail-making test } \\
\text { Part B (sec) }\end{array}$ & $\begin{array}{l}112.43 \pm \\
14.15\end{array}$ & $\begin{array}{c}123.42 \pm \\
17.41^{*}\end{array}$ & $<0.0001$ & $\begin{array}{c}114.52 \pm \\
15.43\end{array}$ & $\begin{array}{c}124.52 \pm \\
18.29^{*}\end{array}$ & $<0.0001$ & 0.607 \\
\hline $\begin{array}{l}\text { Auditory-verbal } \\
\text { learning test }\end{array}$ & $\begin{array}{c}17.14 \pm \\
1.42\end{array}$ & $\begin{array}{c}17.01 \pm \\
1.22\end{array}$ & 0.389 & $\begin{array}{c}17.47 \pm \\
1.52\end{array}$ & $\begin{array}{c}17.22 \pm \\
1.02\end{array}$ & 0.125 & 0.124 \\
\hline $\begin{array}{l}\text { Digit symbol } \\
\text { substitution test }\end{array}$ & $\begin{array}{c}95.43 \pm \\
7.11\end{array}$ & $\begin{array}{l}95.44 \pm \\
6.15\end{array}$ & 0.989 & $\begin{array}{l}95.44 \pm \\
6.45\end{array}$ & $\begin{array}{c}94.12 \pm \\
7.15\end{array}$ & 0.124 & 0.097 \\
\hline $\begin{array}{l}\text { Verbal fluency } \\
\text { test }\end{array}$ & $\begin{array}{c}18.89 \pm \\
1.02\end{array}$ & $\begin{array}{c}16.81 \pm \\
0.98^{*}\end{array}$ & $<0.0001$ & $\begin{array}{c}18.93 \pm \\
1.15\end{array}$ & $\begin{array}{c}16.72 \pm \\
0.93^{*}\end{array}$ & $<0.0001$ & 0.434 \\
\hline
\end{tabular}

${ }^{*} P<0.05$, compared with BL value (BL = 1 day before surgery; EL = first day 1 month after surgery) 
Table 3: Activity of daily living (toileting) in patients at the time of discharge $(n, \%)$

\begin{tabular}{|c|c|c|c|}
\hline \multirow[t]{2}{*}{ Parameter } & \multicolumn{2}{|c|}{ Anesthesia group } & \multirow{3}{*}{$\begin{array}{c}P- \\
\text { value }\end{array}$} \\
\hline & General & $\begin{array}{c}\text { Subarachnoid } \\
\text { (spinal) }\end{array}$ & \\
\hline & $\mathrm{n}=154$ & $\mathrm{n}=127$ & \\
\hline \multirow{3}{*}{$\begin{array}{l}\text { Total } \\
\text { dependence } \\
\text { Partial } \\
\text { dependence } \\
\text { Independence }\end{array}$} & $48(31)$ & $55(43)^{*}$ & \multirow{3}{*}{0.036} \\
\hline & $51(33)$ & $43(34)$ & \\
\hline & $55(36)$ & $29(23)$ & \\
\hline
\end{tabular}

Age has been the only widely accepted risk factor for development of $\mathrm{POCl}$ [8]. However, there are inconsistencies and controversies surrounding the level of involvement of anesthesia in $\mathrm{POCl}$. Although it has been speculated that general anesthesia could be the cause of $\mathrm{POCl}$, other studies have shown no significant differences in its incidence between patients receiving general and non-general anesthesia [8]. At present, there are inconsistent conclusions regarding comparative incidence of $\mathrm{POCl}$ in patients receiving general anesthesia and subarachnoid (spinal) anesthesia. The results obtained in this study showed that there were no significant differences in NAB on the first day 1 month after surgery between general and subarachnoid (spinal) anesthesia groups. Patients who received subarachnoid (spinal) anesthesia had significantly higher dependency for toileting at the time of discharge than those who received general anesthesia. These results are not in agreement with those obtained in previous studies involving Greek, Turkish and Japanese patients $[1,6,19]$. In this study, the TMT scores were within normal limit. It has been reported that pre-existing neurocognitive impairments, preoperative demographic characteristics, preoperative clinical condition, and operative characteristics of patients affect TMT scores [20-22]. The results of this study indicate that subarachnoid (spinal) anesthesia worsened the ADL (toileting) of patients after proximal femoral fracture surgery. This finding is not in agreement with those of a previous study [23]. Spinal anesthesia disturbs bladder function [24]. It interrupts micturition reflex via blockage of efferent fibers and afferent nerves [23]. Higher Charlson Comorbidity Index scores are associated with a disturbance of daily living (toileting) after proximal femoral fracture surgery in elderly patients [24]. General and spinal anesthesia have been shown to slow the recovery of bladder functions in elderly patients after proximal femoral fracture surgery.

There was no significant difference in the number of patients who came down with postoperative delirium between the two anesthesia groups. These results may have been due to the complexity of the surgical procedure, and they are in agreement with those of a randomized trial involving Greek patients [1].

\section{Limitations of the study}

The likely limitations of this study are: (1) small sample size/population; (2) non-inclusion of a normal control group; (3) short follow-up period; (4) failure to carry out multivariate analysis for an independent predictor of postoperative cognitive dysfunction and delirium; (5) non-inclusion of other ADL parameters; (6) failure to carry out comparison of hemodynamic parameters and postoperative pain management; (7) analysis of ADL (toileting) data of patients who stayed in hospital only; (8) use of a single population (Han Chinese); and (9) failure to include other surgical parameters that could affect postoperative cognitive dysfunction.

\section{CONCLUSION}

The results obtained in this study suggest that general and subarachnoid (spinal) anesthesia do not cause postoperative delirium and cognitive dysfunction in elderly Chinese patients who underwent proximal femoral fracture surgery.

\section{DECLARATIONS}

\section{Acknowledgement}

The authors are grateful to the nursing, psychiatrics, and anesthesiology staff of the Suzhou Ninth People's Hospital, Soochow University, Suzhou, Jiangsu, China for their support.

\section{Availability of data and materials}

The datasets used and analyzed during the current study available from the corresponding author on reasonable request.

\section{Conflict of interest}

The authors declared that they have no conflict of interest or any other competing interest regarding results and/or discussion reported in the research.

\section{Contribution of authors}

Both authors have read and approved the manuscript for publication. Wei-Xia Ren was project administrator, contributed to 
methodology, literature review, resources, investigation, and supervision of the study. RanRan Wu contributed to methodology, literature review, resources, formal analysis, and data curation of the study, draft and edited the manuscript for intellectual content. Both authors agree to be accountable for all aspects of work ensuring integrity and accuracy.

\section{Open Access}

This is an Open Access article that uses a funding model which does not charge readers or their institutions for access and distributed under the terms of the Creative Commons Attribution License (http://creativecommons.org/licenses/by/ 4.0) and the Budapest Open Access Initiative (http://www.budapestopenaccessinitiative.org/rea d), which permit unrestricted use, distribution, and reproduction in any medium, provided the original work is properly credited.

\section{REFERENCES}

1. Tzimas $P$, Samara E, Petrou A, Korompilias A, Chalkias $A$, Papadopoulos $G$. The influence of anesthetic techniques on postoperative cognitive function in elderly patients undergoing hip fracture surgery: General vs spinal anesthesia. Injury 2018; 49(12): 2221-2226.

2. Wang $W$, Wang $Y$, Wu $H$, Lei L, Xu S, Shen $X$, Guo $X$, Shen $R$, Xia $X$, Liu $Y$, et al. Postoperative cognitive dysfunction: Current developments in mechanism and prevention. Med Sci Monit 2014; 20: 1908-1912.

3. Strom C, Rasmussen LS, Sieber FE. Should general anaesthesia be avoided in the elderly? Anaesthesia 2014; 69(Suppl 1): 35-44.

4. Silbert B, Evered L, Scott DA. Cognitive decline in the elderly: Is anaesthesia implicated? Best Pract Res Clin Anaesthesiol 2011; 25(3): 379-393.

5. Zywiel MG, Prabhu A, Perruccio AV, Gandhi R. The influence of anesthesia and pain management on cognitive dysfunction after joint arthroplasty: A systematic review. Clin Orthop Relat Res 2014; 472(5): 1453-1466.

6. Edipoglu IS and Celik F. The associations between cognitive dysfunction, stress biomarkers, and administered anesthesia type in total knee arthroplasties: Prospective, randomized trial. Pain Physician 2019; 22(5): 495-507.

7. Davis $N$, Lee M, Lin AY, Lynch L, Monteleone M, Falzon L, Ispahany N, Lei S. Postoperative cognitive function following general versus regional anesthesia: a systematic review. J Neurosurg Anesthesiol 2014; 26(4): 369-376.

8. Guay J. General anaesthesia does not contribute to longterm post-operative cognitive dysfunction in adults: $A$ meta-analysis. Indian J Anaesth 2011; 55(4): 358-363.
9. Guay J, Parker MJ, Gajendragadkar PR, Kopp S. Anaesthesia for hip fracture surgery in adults. Cochrane Database Syst Rev 2016; 2(2): 1-85.

10. Gonzalez-Zabaleta J, Pita-Fernandez S, Seoane-Pillado $T$, Lopez-Calvino B, Gonzalez-Zabaleta JL. Dependence for basic and instrumental activities of daily living after hip fractures. Arch Gerontol Geriatr 2015; 60(1): 66-70.

11. Shenkin SD, Fox C, Godfrey M, Siddiqi N, Goodacre S, Young J, Anand A, Gray A, Hanley J, MacRaild A, et al. Delirium detection in older acute medical inpatients: $A$ multicentre prospective comparative diagnostic test accuracy study of the $4 A T$ and the confusion assessment method. BMC Med 2019; 17(1): 138-1-13814.

12. Peng $X$, Liu R, Zhu $Y, X u Q, L i J$. Sevoflurane versus isoflurane for postoperative cognitive dysfunction of patients undergoing major cardiac surgeries: $A$ prospective cohort study. Indian J Pharm Educ 2019; 53(4): 710-715.

13. Freedland KE, Steinmeyer BC, Carney RM, Rubin EH, Rich MW. Use of the PROMIS $₫$ Depression scale and the Beck Depression Inventory in patients with heart failure. Health Psychol 2019; 38(5): 369-375.

14. Yan L, Liu Q, Zhu Y, Zhou $M$, Wang $H$, Qin X, Wang $L$. Association of preexisting neurocognitive impairments and perioperative neurocognitive disorders for hip joint replacement surgery: A prospective cohort study. Med Sci Monit 2019; 22: 4617-4626.

15. Li X, Zhou Z, Jia S, Hou C, Zheng W, Rong P, Jiao J. Cognitive study on Chinese patients with idiopathic REM sleep behavior disorder. J Neurol Sci 2016; 366: 82-86.

16. RAVLT Adult Calculator. Available from: http://www. beaumont.ie/media/RAVLTAdultcalculator1.x Is [Access on 13 August 2020].

17. Shi C, Wang G, Tian F, Han X, Sha S, Xing $X, Y u X$. Reliability and validity of Chinese version of perceived deficits questionnaire for depression in patients with MDD. Psychiatry Res 2017; 25: 319-324.

18. Liu J, Zhang F, Wang $Y, W u$ D. Prevalence and association of depression with uremia in dialysis population: A retrospective cohort analysis. Medicine 2020; 99(24): 1-e20401-6-e20401.

19. Egawa J, Inoue S, Nishiwada T, Tojo T, Kimura $M$, Kawaguchi $T$, Taniguchi S, Furuya $H$, Kawaguchi $M$. Effects of anesthetics on early postoperative cognitive outcome and intraoperative cerebral oxygen balance in patients undergoing lung surgery: A randomized clinical trial. Can J Anaesth 2016; 63(10): 1161-1169.

20. Corcoles-Jimeez MP, Villada-Munera A, Del EgidoFernandez MA, Candel-Parra E, Moreno-Moreno M, Jimenez-Sanchez MD, Pina-Martínez A. Recovery of activities of daily living among older people one year after hip fracture. Clin Nurs Res 2015; 24(6): 604-623.

21. Wei B, Zhang $H, X u M$, Li M, Wang J, Zhang LP, Guo $X Y$, Zhao YM, Zhou F. Effect of different anesthetic methods on postoperative outcomes in elderly patients undergoing hip fracture surgery. Journal of Peking

Trop J Pharm Res, February 2021; 20(2): 438 
University (Health Sciences) 2017; 49(6): 1008-1013 [Article in Chinese].

22. Ravi $B$, Pincus $D$, Choi S, Jenkinson $R$, Wasserstein $D N$, Redelmeier DA. Association of duration of surgery with postoperative delirium among patients receiving hip fracture repair. JAMA Netw Open 2019; 2(2): 1e190111-11-e190111.

23. Fukuda T, Imai S, Nakadera M, Wagatsuma $Y$, Horiguchi $H$. Postoperative daily living activities of geriatric patients administered general or spinal anesthesia for hip fracture surgery: A retrospective cohort study. J Orthop Surg 2018; 26(1): 1-2309499017754106-92309499017754106.

24. Zanfini BA, Paradisi G, Savone R, Catarci S, Quagliozzi L, De Waure C, Caruso A, Draisci G. Bladder function after spinal anesthesia for cesarean section: An urodynamic evaluation. Eur Rev Med Pharmacol Sci 2012; 16(11): 1525-1529. 